\section{The Holobiont Blindspot: Relating Host-Microbiome Interactions to Cognitive Biases and the Concept of the "Umwelt"}

\author{
Jake M. Robinson ${ }^{1,2,3 *}$ and Ross Cameron ${ }^{1}$ \\ ${ }^{1}$ Department of Landscape Architecture, The University of Sheffield, Sheffield, United Kingdom, ${ }^{2}$ In vivo Planetary Health, \\ Worldwide Universities Network (WUN), West New York, NJ, United States, ${ }^{3}$ The Healthy Urban Microbiome Initiative \\ (HUMI), Adelaide, SA, Australia
}

Cognitive biases can lead to misinterpretations of human and non-human biology and behavior. The concept of the Umwelt describes phylogenetic contrasts in the sensory realms of different species and has important implications for evolutionary studies of cognition (including biases) and social behavior. It has recently been suggested that the microbiome (the diverse network of microorganisms in a given environment, including those within a host organism such as humans) has an influential role in host behavior and health. In this paper, we discuss the host's microbiome in relation to cognitive biases and the concept of the Umwelt. Failing to consider the role of host-microbiome (collectively termed a "holobiont") interactions in a given behavior, may underpin a potentially important cognitive bias - which we refer to as the Holobiont Blindspot. We also suggest that microbially mediated behavioral responses could augment our understanding of the Umwelt. For example, the potential role of the microbiome in perception and action could be an important component of the system that gives rise to the Umwelt. We also discuss whether microbial symbionts could be considered in System 1 thinking - that is, decisions driven by perception, intuition and associative memory. Recognizing Holobiont Blindspots and considering the microbiome as a key factor in the Umwelt and System 1 thinking has the potential to advance studies of cognition. Furthermore, investigating Holobiont Blindspots could have important implications for our understanding of social behaviors and mental health. Indeed, the way we think about how we think may need to be revisited.

Keywords: Umwelt, cognition, microbiome, system one thinking, Holobiont Blindspot, cognitive bias

\section{INTRODUCTION}

It is well established that humans are prone to making systematic cognitive errors or "biases" for example, the susceptibility to overestimate how much one understands about the world (Kahneman et al., 1998; Barton et al., 2016). Some authors (particularly those working within western scientific frameworks) have suggested that anthropomorphism - the heuristic act of attributing human-centric phenotypes to both non-human animals and inanimate phenomena can lead to misunderstandings of non-human biological processes and behaviors (Burghardt, 2004; Farina, 2012; Bueno-Guerra, 2018). Furthermore, the hierarchical view of nature that positions humans as the pinnacle of species is yet another cognitive bias that may inhibit our understanding and appreciation of the complex interrelated ecologies of biology and behavior. 
It should, however, be acknowledged that many Indigenous societies view humans and the rest of nature as a complex web of interconnected subjects (and not discrete, hierarchical objects) (Gratani et al., 2016; De Castro, 2019; Robinson et al., 2020, Manuscript In Review).

The concept of the Umwelt was first coined by Jakob Von Uexküll in the early 20th century to describe phylogenetic contrasts in the sensory realms of different species, and the species-specific interactions that occur between the brain, the body and the environment (Von Uexküll et al., 1899; Von Uexküll, 1934/1957; Partan and Marler, 2002). Historically, the Umwelt was divided into the Merkwelt (perceptual world) and the Wirkwelt (effector/action world) to define an animal's sensory unit, from perception to behavior. However, BuenoGuerra (2018) recently proposed a broadening of the Umwelt concept to include the social sphere or the Sozialwelt. An important justification for this proposal was that social dynamics can profoundly influence perception and action. Moreover, transferring the human phenotype of "cooperative bonding" to their chimpanzee Pan troglodytes subjects, led to delusive generalizations in social behaviors (including inconsistent results in task solving with cooperative set-ups) i.e., evolutionary behavioral pathways may not be identical in other species.

In recent years, microbial ecology has seen a rapid expansion in knowledge - attributed in part, to technological advances such as high-throughput DNA sequencing and streamlined bioinformatics (the science of collecting and analyzing complex biological data) (Wooley and Ye, 2010; Stres and Kronegger, 2019). It has recently been suggested that the microbiome - the diverse network of microorganisms in a given environment has an influential role in the behavior and health of humans and non-human organisms (Rook, 2013; Cryan et al., 2019; Sherwin et al., 2019). Indeed, microorganisms have recently been implicated in host behavioral manipulation through the olfactory system, the microbiota-gut-brain axis, and other biochemical pathways (Davidson et al., 2020; O’Donnell et al., 2020; Robinson and Breed, 2020). Furthermore, it is thought that exposure to the environmental microbiome plays an essential role in "educating" and regulating innate and adaptive immunity (e.g., via modulation of regulatory $\mathrm{T}$ cells), and microorganisms are known to provide a range of functional, physiological roles (Rook, 2013; Rook et al., 2014; Prescott et al., 2017; Chen et al., 2020).

In this perspective article, we discuss host-microbiome interactions in relation to cognitive biases and the concept of the Umwelt. We suggest that microbially mediated host behavioral phenotypes could provide the basis for another conceptual augmentation of the Umwelt, that is, to include explicit considerations for the microbiome in the realms of perception and action. Failing to consider the role of interactions between the host and their microbiome (collectively termed a "holobiont") in a given behavior could underpin a potentially important cognitive bias which we refer to as the Holobiont Blindspot. This bias could lead to misinterpretations and delusive generalizations in animal (including humans) and non-animal behavioral studies. This is important from a third-person perspective (e.g., the researcher studying another organism or population). However, we also discuss whether microbial symbionts could have an influence from a first-person perspective (integral to the concept of the Umwelt) and in the dimension of System 1 thinking - that is, decisions driven by perception, intuition and associative memory, as popularized by Daniel Kahneman (Kahneman, 2001). If this is the case, there could be important social ramifications, and the concepts of perception and intuition may need to be revisited.

Recognizing the Holobiont Blindspot, and considering the microbiome as a key component of system that gives rise to the Umwelt and Systems 1 thinking, has the potential to advance studies of cognition and social behavior. Moreover, investigating these concepts could have important social ramifications by restructuring the way we interpret and empathize with social behaviors, and potentially how we understand mental health conditions.

\section{THE HOLOBIONT BLINDSPOT AND THE UMWELT}

Growing evidence suggests that the microbiome can have a considerable influence on the behavior of humans and non-human organisms (Farzi et al., 2019; Huang et al., 2019; Ezra-Nevo et al., 2020). Although the mechanisms of microbially mediated host behavioral responses are not fully understood, several biochemical pathways have been proposed. One pathway that has received considerable attention is the microbiota-gutbrain axis (Cryan et al., 2019; Lyte et al., 2020). This refers to the bidirectional communication system linking the central and enteric nervous system to the microorganisms in the gut via the vagus nerve (Ueno and Nakazato, 2016; Breit et al., 2018). Microorganisms in the gut produce an array of metabolic by-products that can stimulate peptide hormone secretion and directly activate the vagus afferents connecting the gut to the brain (Lach et al., 2018; Fülling et al., 2019). Consequently, it has been suggested that microorganisms can metaphorically "hijack" the gut-brain communication highway and influence a range of neuronal processes that result in behavioral responses (Vuong et al., 2017; Davidson et al., 2018). Gut microorganisms can also synthesize compounds such as serotonin (5-hydroxytryptamine), acetylcholine, and peptidoglycan which can penetrate the blood-brain barrier via the systemic circulatory system (Petra et al., 2015; Logsdon et al., 2018; Cryan et al., 2019).

A recent animal study demonstrated that gut bacteria can mimic the functions of cognate host receptor molecules to override host sensory decisions (O’Donnell et al., 2020). In this study, a commensal gut bacterium Providencia sp., produced a neuromodulator called tyramine. This compound is thought to act upon the host's olfactory system, modulating aversive responses to certain odors. This process potentially drives mutually beneficial food decisions - i.e., the host is manipulated into choosing a food source that benefits both the animal host and the commensal bacteria.

This study is only one of several recent animal studies demonstrating modulation of host behavior by commensal bacteria. For example, the bacteria Acetobacter pomorum and 
Lactobacillus sp., have been shown to work synergistically to manipulate host feeding decisions in Drosophila melanogaster (Leitão-Gonçalves et al., 2017; Pasquaretta et al., 2018). Other D. melanogaster studies support the notion of behavioral manipulation via olfactory pathways - e.g., individuals can be attracted to compounds secreted by Saccharomyces cerevisiae and Lactobacillus plantarum but repelled by those from Acetobacter malorum (Qiao et al., 2019). Moreover, microorganisms are thought to trigger transcriptional olfactory responses in mice Mus sp., and zebrafish Danio rerio (Casadei et al., 2019; Cryan et al., 2019). Host sociability and breeding can also be influenced by the microbiome through the mediation of behavioral responses that influence inter-host transmission (Stilling et al., 2014; Wong et al., 2015; Shropshire and Bordenstein, 2016; Sherwin et al., 2019; Simon et al., 2019).

The intricate relationships between host and commensal microorganisms can be framed from a "hologenomic" perspective. A holobiont, a term first coined by Margulis (1990) is defined as a "biomolecular network composed of the host plus its associated microbes [.], and their collective genomes forge a hologenome" (Bordenstein and Theis, 2015).

It is important to acknowledge that the debate is ongoing as to how the hologenome concept of evolution may unfold. For example, an important criticism of this concept is that more evidence is needed to support the notion of vertical transmission of microbiota (from generation to generation) (Robinson and Breed, 2020). However, as Rosenberg and ZilberRosenberg (2020) point out, there is some evidence to support this concept. For example, human individuals can retain the same ancestral Helicobacter pylori strains, even after migrating to different localities (Achtman et al., 1999; Falush et al., 2003), and other corroborating studies were put forward by Rosenberg and Zilber-Rosenberg (2020) (e.g., Ochman et al., 2010; Goodrich et al., 2016; Moeller et al., 2016). Nonetheless, perhaps a more compelling argument for the hologenomic evolutionary process and its associated behavioral implications, arrives from the notion of functional associations. For example, it is likely that evolution has favored host-microbiome functional associations that precisely reproduce the biochemical networks that give rise to host behaviors across generations (Doolittle and Booth, 2017). Indeed, Suárez (2020) and Suárez and Triviño (2020) argue that in terms of defining the holobiont as an evolutionary unit, less emphasis should be placed on the microbiome's lineages or taxa, and more on its functional traits (encoded by the organisms' genes) - referred to as the stability of traits concept.

Whilst the precise evolutionary mechanisms still need to be unraveled, one element is clear: the microbiome's functional traits can have a considerable influence on host perception of stimuli (Merkwelt) via sensory influences (e.g., olfactory processes), and subsequent behavioral responses or decision-making (Wirkwelt). Therefore, this concept could have important implications for evolutionary studies of cognition and may potentially present a cognitive bias if not considered. Here, we propose the Holobiont Blindspot to describe this potential cognitive bias. This cognitive bias - also known as a "blindspot" - could conceivably lead to misinterpretations and delusive generalizations as demonstrated by Bueno-Guerra's (2018) Sozialwelt. Indeed, understanding the full sensory spectrum that an animal can perceive (e.g., one element being microbially derived odors), along with the unique drivers of perception and response (e.g., those functionally mimicked by commensal microorganisms) could aid in the selection of appropriate controls and relevant stimuli in behavioral studies. Just as a cognitive bias can manifest through the attribution of human-centric phenotypes to nonhuman animals, treating holobionts as individual subjects divorced from any cognitive influence via symbiotic interactions could also be viewed in this manner. It is also important to note here that plants and even microbes can themselves be holobionts. For example, this was articulated in a recent book, the Entangled Life (Sheldrake, 2020), with the following paraphrased passage:

\begin{abstract}
"I attended a conference in Panama on tropical microbes. Someone got up to talk about a group of plants that produced a certain group of chemicals in their leaves. Until recently, the chemicals had been thought of as a defining characteristic of that group of plants. However, it transpired that the chemicals were actually made by fungi that lived in the leaves of the plants. Our idea of the plants had to be redrawn. Another researcher interjected, suggesting that it may not be the fungi living inside the leaf that produced these chemicals, but the bacteria living inside the fungi. The notion of the individual had deepened and expanded beyond recognition. To talk about individuals made no sense anymore" (Sheldrake, 2020, p. 18).
\end{abstract}

Whilst the idea of a Holobiont Blindspot was initially conceived with the third-person view in mind (e.g., the researcher studying the holobiont), we can also consider the Holobiont Blindspot from the first-person perspective - which is considered integral to the concept of the Umwelt (Baggs and Chemero, 2019). Indeed, in the human dimension the Holobiont Blindspot can be positioned in the realm of System 1 thinking. This refers to a conceptual branch of cognition characterized by "fast and automatic thinking" popularized by Daniel Kahneman (Kahneman, 2001; Moran, 2012). It is important to note that running contra to System 1 thinking is System 2 thinking - a term used to describe the controlled and deliberate mode of thought (Rottenstreich et al., 2007). However, we find the former to be more relevant to the concepts and scope of this work.

Indeed, potential cognitive biases could occur if we assume a System 1-based response in the perception-action cycle (a central principle of the Umwelt, also known as the "functional loop") as being purely the result of human intuition and/or associative memory, when it could conceivably be a microbially mediated behavioral response (Figure 1). For example, via olfactory receptors, leading to an aversive behavior.

As discussed, microorganisms have been shown to influence decision-making in animals via olfactory processes (Qiao et al., 2019; O’Donnell et al., 2020). In humans, the olfactory system plays a major role in social behavior. For example, olfactory cues can significantly influence memory recall, purchasing behavior, appetite and sexual arousal (Borg et al., 2014; Jacobson et al., 2019; Sandell, 2019). As such, the Holobiont Blindspot could potentially have important social ramifications. To illustrate this, we present a brief thought experiment below: 


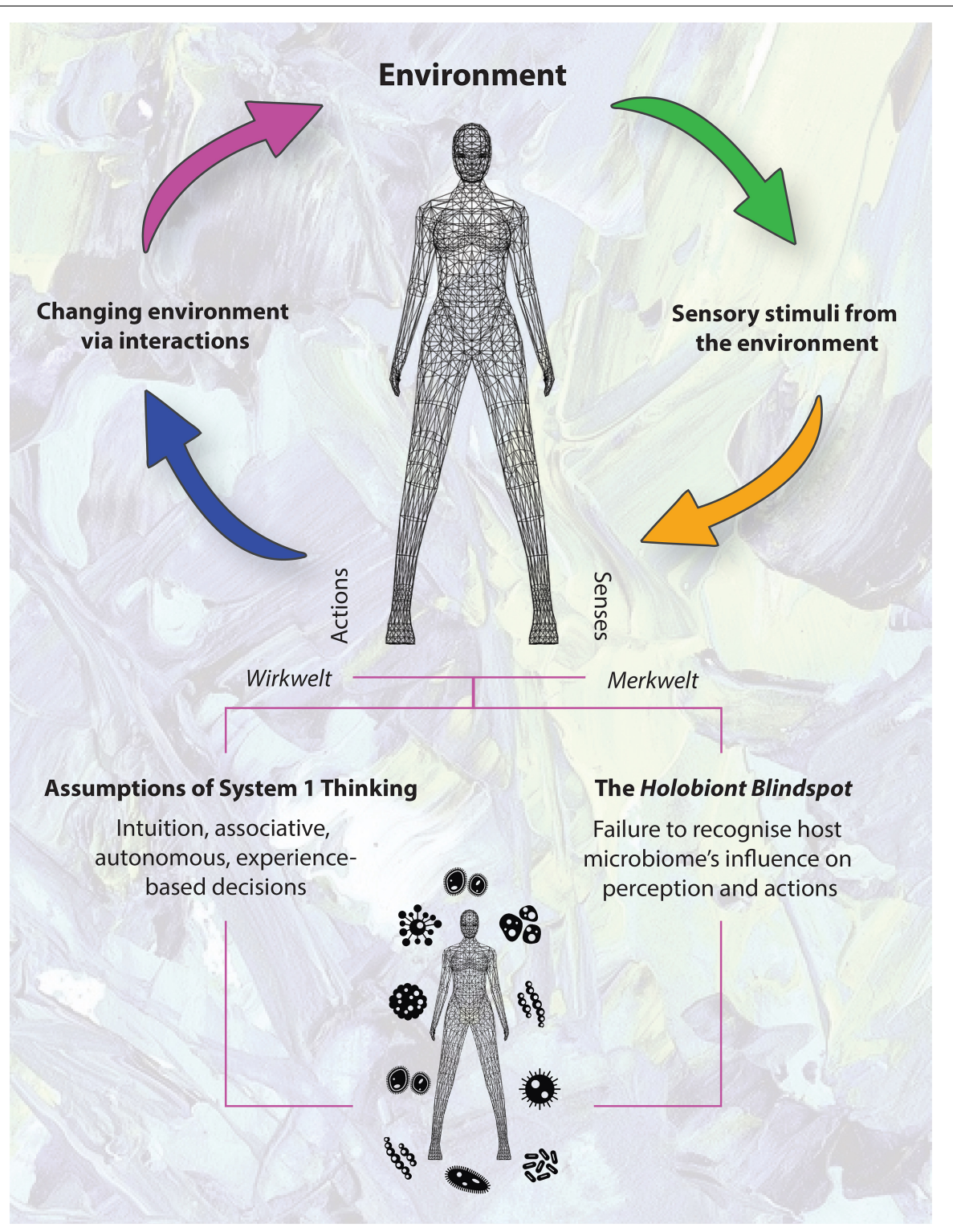

FIGURE 1 | The perception-action cycle and assumptions of System 1 Thinking. Failure to recognize potential microbiome influences in perception and action is the Holobiont Blindspot.

1. Changes to (or inter-individual differences in) the human microbiome via environmental disturbances (e.g., pollution exposure; dietary change; antibiotics) $\rightarrow 2$. Changes to odor perception in the human host $\rightarrow 3$. Changes to preferences (e.g., human odors as "attractants") $\rightarrow$ 4. Could the hypothetical individual become less attracted to another individual as a result of this microbially mediated driver? $\rightarrow 5$. Theoretically, this could have important social implications (e.g., leading to relationship issues).

Indeed, it has previously been demonstrated that the microbiome can influence mating preferences in the D. melanogaster model. For example, Sharon et al. (2010) divided a population of $D$. melanogaster and reared one half of the population on a molasses-based medium and the other on a starch-based medium. When the populations were mixed together, the flies reared on molasses preferred to mate with other "molasses flies" and the "starch flies" preferred to mate with other starch flies. However, subsequent treatment with antibiotics abolished mating preference in the flies suggesting the microbiome was responsible for the preferences. When the flies were inoculated with microbiota from the media, this phenomena was confirmed. It is thought that the microbiome has a role in changing the levels of sex hormones, thus influencing mating behavior.

Other examples could have important health implications such as potential effects on food selection or influencing our 
choices to spend time in certain environments (salutogenic or otherwise). Indeed, the Lovebug Effect (Robinson and Breed, 2020) was recently proposed as a microbially mediated mechanism to help explain our affinity for nature - i.e., could a deficiency in the diversity and functional potential of gut microbiota influenced our decision, via the microbiota-gut-brain axis, to spend time in natural environments where immune supporting microorganisms are abundant? The Umwelt of an individual is shaped by the environments the individual resides in, and by the interactions they engage in Baggs and Chemero (2019). Therefore, microbial drivers of behavior could profoundly influence the Umwelt of the individual.

Our microbiome is also thought to affect our mood (Bastiaanssen et al., 2020; Talbott et al., 2020). Could this have implications for our relationships and motivations, with downstream effects, for example, on work performance and mental health? After all, in the case of depression, oftentimes people do not know (and so cannot articulate) why they feel depressed (Cheng et al., 2020) - could this also be a Holobiont Blindspot? If there is a microbial link to depression as suggested by researchers (Foster and Neufeld, 2013), investigating interventions (e.g., through microbial therapeutics) to address this could play an important role in managing mental health in the future (Long-Smith et al., 2020). Several studies have also shown that fecal microbiota transplants can result in the transfer of behavioral phenotypes such as anxiety-like behaviors and anhedonia (inability to feel pleasure) (Bercik et al., 2011; Kelly et al., 2016; Cryan et al., 2019). One study found that altering microbiota in germ-free mice led to changes in hippocampal brain-derived neurotropic factor (a protein involved in brain development and regulation) and subsequent differences in exhibited anxiety-like behaviors (Bercik et al., 2011). Therefore, the Holobiont Blindspot could conceivably lead to an inadequate explanation of anxietylike and anhedonic behaviors, whereas taking host-microbiome interactions into account could provide a much richer and more accurate explanation. Indeed, microbially mediated anhedonic behaviors is another potential pathway to which microbial drivers could affect one's Umwelt i.e., through altering the perception of pleasure.

Our microbial symbionts also affect cognitive traits such as memory, which could affect host memory of food location, as recently shown in wild vertebrates (Davidson et al., 2020). This could have important dietary and health implications, and in humans could conceivably cause relationship issues e.g., if one partner regularly forgets an important date or forgets to express affection. Further investigations into these theoretical Holobiont Blindspots could change the way we understand and empathize with certain social behaviors. As System 1 thinking plays a role in systematic errors through reasoning (Kannengiesser and Gero, 2019; Preisz, 2019), studies aimed at ascertaining the potential effects (deleterious or otherwise) of a host's microbiome in this process could be extremely valuable. If part of our perception and intuition is influenced by "other" agents (i.e., microorganisms) considered to be constituents of the holobiont, could this change the way we view perception and intuition? Or even the way we view each other - e.g., procuring empathy for decisions "out of our control," or mitigating intuitions/impulses that lead to unfavorable actions? The Holobiont Blindspot could also be related to the psychological model of "free will," which has implications for the notions of responsibility and punishment. Indeed, alterations to certain regions of the brain such as the prefrontal cortex can "produce an individual capable of differentiating right from wrong but who, nonetheless, is organically incapable of appropriately regulating their behavior" (Zeki et al., 2004, p. 1). Could our microbiome affect our perception-action cycle and System 1 responses via the modulation of irresistible impulses, and should this be taken into account when considering responsibility and the notions of "free will" and determinism?

Following a similar logic to the recently proposed Sozialwelt, we argue that more attention should be given to the hidden components of the system that could influence an organism's Umwelt (e.g., the microbiome). As suggested, microorganisms could have an important role to play in the Umwelt through perception (Merkwelt) and action (Wirkwelt). We should be alert to the possibility of a Holobiont Blindspot and consider that "thinking" is not simply a brain-centric process microorganisms may play a role in a complex suite of interactions between the brain, body and environment. Indeed, the Holobiont Blindspot and the Umwelt are also relevant through the lens of biological individuality. If the Umwelt refers to an organism's perceptual world, and the individuality of an organism is in question - particularly given that holobionts can be considered to be individuals and ecosystems simultaneously (Suárez and Stencel, 2020) - then is the Umwelt the perceptual world of an organism or an ecosystem? The Holobiont Blindspot questions the very mechanisms and boundaries of the Umwelt and even the notions of free will and determinism. It will hopefully generate discussion about how far the microbiome can go in terms of explaining "our" behavior and evolution.

\section{CONCLUSION}

In this perspective article, we have discussed the importance of considering microbial influences on what is traditionally considered to be an organism's perceptual world (Merkwelt) and action world (Wirkwelt) - and in the absence of doing so, there is potential for the Holobiont Blindspot (a cognitive bias) which could have important social ramifications. Indeed, it could be important to study the Holobiont Blindspot from both the third-person perspective (e.g., a researcher studying animal populations) and from the first-person view (e.g., comprehending the microbiome's influence on our own intuition/behavioral responses and even our mental health). Recognizing the Holobiont Blindspot and investigating how the microbiome may influence the Umwelt and cognition, could also provide new and important insights in evolutionary studies of cognition and social behavior. The Holobiont Blindspot may inhibit our understanding and appreciation of the complex interrelated ecologies of biology and behavior. The way we think about how we think may need to be revisited. 
"Beneath our superficial differences we are, all of us, walking communities of bacteria. The world shimmers, a pointillist landscape made of tiny living beings." (Lynn Margulis, in Margulis and Sagan, 1986, p. 191).

\section{AUTHOR CONTRIBUTIONS}

JR conceived, designed, and wrote the manuscript, and produced the figure and data visualizations. JR and RC contributed

\section{REFERENCES}

Achtman, M., Azuma, T., Berg, D. E., Ito, Y., Morelli, G., Pan, Z. J., et al. (1999). Recombination and clonal groupings within Helicobacter pylori from different geographical regions. Mol. Microbiol. 32, 459-470. doi: 10.1046/j.1365-2958. 1999.01382.x

Araújo, D., Hristovski, R., Seifert, L., Carvalho, J., and Davids, K. (2019). Ecological cognition: expert decision-making behaviour in sport. Int. Rev. Sport Exerc. Psychol. 12, 1-25. doi: 10.1080/1750984x.2017.1349826

Baggs, E., and Chemero, A. (2019). The Third Sense of Environment. New York, NY: Routledge, 5-20. doi: 10.4324/9780429316128-2

Barton, M., Symborski, C., Quinn, M., Morewedge, C. K., Kassam, K. S., and Korris, J. H. (2016). The use of theory in designing a serious game for the reduction of cognitive biases. Transact. Digital Games Res. Assoc. 17, 1-15. doi: 10.26503 /todigra.v2i3.53

Bastiaanssen, T. F., Cussotto, S., Claesson, M. J., Clarke, G., Dinan, T. G., and Cryan, J. F. (2020). Gutted! Unraveling the role of the microbiome in major depressive disorder. Harv. Rev. Psychiatry 28, 26-39. doi: 10.1097/hrp. 0000000000000243

Bercik, P., Denou, E., Collins, J., Jackson, W., Lu, J., Jury, J., et al. (2011). The intestinal microbiota affect central levels of brain-derived neurotropic factor and behavior in mice. Gastroenterology 141, 599-609. doi: 10.1053/j.gastro. 2011.04.052

Bordenstein, S. R., and Theis, K. R. (2015). Host biology in light of the microbiome: ten principles of holobionts and hologenomes. PLoS Biol. 13:e1002226. doi: 10.1371/journal.pbio.1002226

Borg, C., Oosterwijk, T. A., Lisy, D., Boesveldt, S., and de Jong, P. J. (2014). The influence of olfactory disgust on (Genital) sexual arousal in men. PLoS One 14:e0213059. doi: 10.1371/journal.pone.0213059

Breit, S., Kupferberg, A., Rogler, G., and Hasler, G. (2018). Vagus nerve as modulator of the brain-gut axis in psychiatric and inflammatory disorders. Front. Psychiatry. 9:44-59. doi: 10.3389/fpsyt.2018.00044

Bueno-Guerra, N. (2018). How to apply the concept of umwelt in the evolutionary study of cognition. Front. Psychol. 9:2001. doi: 10.3389/fpsyg.2018.02001

Burghardt, G. M. (2004). Ground rules for dealing with anthropomorphism. Nature 430:15. doi: 10.1038/430015b

Casadei, E., Tacchi, L., Lickwar, C. R., Espenschied, S. T., Davison, J. M., Muñoz, P., et al. (2019). Commensal bacteria regulate gene expression and differentiation in vertebrate olfactory systems through transcription factor REST. Chem. Senses 44, 615-630. doi: 10.1093/chemse/bjz050

Chen, W., Zhang, S., Wu, J., Ye, T., Wang, S., Wang, P., et al. (2020). Butyrateproducing bacteria and the gut-heart axis in atherosclerosis. Clin. Chim. Acta 507, 236-241. doi: 10.1016/j.cca.2020.04.037

Cheng, J. M., Batten, G. P., Cornwell, T., and Yao, N. (2020). A qualitative study of health-care experiences and challenges faced by ageing homebound adults. Health Expect. 23, 934-942. doi: 10.1111/hex.13072

Cryan, J. F., O'Riordan, K. J., Cowan, C. S., Sandhu, K. V., Bastiaanssen, T. F., Boehme, M., et al. (2019). The microbiota-gut-brain axis. Physiol. Rev. 99, 1877-2013. doi: 10.1152/physrev.00018.2018

Daiber, A., Kröller-Schön, S., Frenis, K., Oelze, M., Kalinovic, S., Vujacic-Mirski, K., et al. (2019). Environmental noise induces the release of stress hormones and inflammatory signaling molecules leading to oxidative stress and vascular dysfunction-Signatures of the internal exposome. Biofactors 45, 495-506. doi: 10.1002/biof.1506 to manuscript internal critical review process and revisions, and read and approved the submitted version. Both authors contributed to the article and approved the submitted version.

\section{FUNDING}

JR was undertaking a Ph.D. through the White Rose Doctoral Training Partnership (WRDTP), funded by the Economic and Social Research Council (ESRC). Grant code: ES/J500215/1.

Dantzer, R., Cohen, S., Russo, S. J., and Dinan, T. G. (2018). Resilience and immunity. Brain Behav. Immun. 74, 28-42. doi: 10.1016/j.bbi.2018.08.010

Davidson, G., Wiley, N., Cooke, A. C., Johnson, C. N., Fouhy, F., Reichert, M. S., et al. (2020). Diet-induced changes to host gut microbiota are linked to foraging innovation in a wild bird. bioRxiv [Preprint]. 827741.

Davidson, G. L., Cooke, A. C., Johnson, C. N., and Quinn, J. L. (2018). The gut microbiome as a driver of individual variation in cognition and functional behaviour. Philos. Trans. R. Soc. Lond. B Biol. Sci. 373:20170286. doi: 10.1098/ rstb.2017.0286

Davidson, G. L., Raulo, A., and Knowles, S. C. (2020). Identifying microbiomemediated behaviour in wild vertebrates. Trends. Ecol. Evol. 35, 972-980. doi: 10.1016/j.tree.2020.06.014

De Castro, E. V. (2019). Exchanging perspectives: the transformation of objects into subjects in Amerindian ontologies. Common. Knowl. 25, 21-42. doi: 10. 1215/0961754X-7299066

Doolittle, W. F., and Booth, A. (2017). It's the song, not the singer: an exploration of holobiosis and evolutionary theory. Biol. Philos. 32, 5-24. doi: 10.1007/s10539016-9542-2

Ezra-Nevo, G., Henriques, S. F., and Ribeiro, C. (2020). The diet-microbiome tango: how nutrients lead the gut brain axis. Curr. Opin. Neurobiol. 62, 122-132. doi: $10.1016 /$ j.conb.2020.02.005

Falush, D., Wirth, T., Linz, B., Pritchard, J. K., Stephens, M., Kidd, M., et al. (2003). Traces of human migrations in Helicobacter pylori populations. Science 299, 1582-1585. doi: 10.1126/science. 1080857

Farina, M. (2012). Louise Barrett, beyond the brain: how body and environment shape animal and human minds. Phenom. Cogn. Sci. 12, 415-421. doi: 10.1007/ s11097-011-9247-6

Farzi, A., Hassan, A. M., Zenz, G., and Holzer, P. (2019). Diabesity and mood disorders: multiple links through the microbiota-gut-brain axis. Mol. Aspects Med. 66, 80-93. doi: 10.1016/j.mam.2018.11.003

Foster, J. A., and Neufeld, K. A. M. (2013). Gut-brain axis: how the microbiome influences anxiety and depression. Trends Neuro 36, 305-312. doi: 10.1016/j. tins.2013.01.005

Fülling, C., Dinan, T. G., and Cryan, J. F. (2019). Gut microbe to brain signaling: what happens in vagus. Neuron. 101, 998-1002. doi: 10.1016/j.neuron.2019. 02.008

Goodrich, J. K., Davenport, E. R., Beaumont, M., Jackson, M. A., Knight, R., Ober, C., et al. (2016). Genetic determinants of the gut microbiome in UK twins. Cell Host Microbe 19, 731-743. doi: 10.1016/j.chom.2016. 04.017

Gratani, M., Sutton, S. G., Butler, J. R., Bohensky, E. L., and Foale, S. (2016). Indigenous environmental values as human values. Cogent Soc. Sci. 2:1185811. doi: 10.1080/23311886.2016.1185811

Gubert, C., Kong, G., Renoir, T., and Hannan, A. J. (2020). Exercise, diet and stress as modulators of gut microbiota: implications for neurodegenerative diseases. Neurobiol. Dis. 134:104621. doi: 10.1016/j.nbd.2019.104621

Huang, T. T., Lai, J. B., Du, Y. L., Xu, Y., Ruan, L. M., and Hu, S. H. (2019). Current understanding of gut microbiota in mood disorders: an update of human studies. Front. Genet. 19:98. doi: 10.3389/fgene.2019.00098

Jacobson, A., Green, E., Haase, L., Szajer, J., and Murphy, C. (2019). Differential effects of BMI on brain response to odor in olfactory, reward and memory regions: Evidence from fMRI. Nutrients. 11:926. doi: 10.3390/nu11040926

Jin, Y., Wu, S., Zeng, Z., and Fu, Z. (2017). Effects of environmental pollutants on gut microbiota. Environ. Pollut. 222, 1-9. doi: 10.1007/978-981-15-4759-1_1 
Kahneman, D., Hirshleifer, D., and Subrahmanyam, A. (1998). A theory of overconfidence, self-attribution, and security market under-and overreaction. J. Finance. 53, 1839-1886. doi: 10.1111/0022-1082.00077

Kahneman, D. A. (2001). Thinking, Fast and Slow. New York, NY: Farrar, Straus and Giroux.

Kannengiesser, U., and Gero, J. S. (2019). Design thinking, fast and slow: a framework for Kahneman's dual-system theory in design. Des. Sci. 5:e10. doi: 10.1017/dsj.2019.9

Karl, J. P., Hatch, A. M., Arcidiacono, S. M., Pearce, S. C., Pantoja-Feliciano, I. G., Doherty, L. A., et al. (2018). Effects of psychological, environmental and physical stressors on the gut microbiota. Front. Microbiol. 9:2013-2187. doi: $10.3389 /$ fmicb. 2018.02013

Kelly, J. R., Borre, Y., O’Brien, C., Patterson, E., El Aidy, S., Deane, J., et al. (2016). Transferring the blues: depression-associated gut microbiota induces neurobehavioural changes in the rat. J. Psychiatr. R. 82, 109-118. doi: 10.1016/ j.jpsychires.2016.07.019

Lach, G., Schellekens, H., Dinan, T. G., and Cryan, J. F. (2018). Anxiety, depression, and the microbiome: a role for gut peptides. Neurotherapeutics 15, 36-59. doi: 10.1007/s13311-017-0585-0

Leitão-Gonçalves, R., Carvalho-Santos, Z., Francisco, A. P., Fioreze, G. T., Anjos, M., Baltazar, C., et al. (2017). Commensal bacteria and essential amino acids control food choice behavior and reproduction. PLoS Biol. 15:e2000862. doi: 10.1371/journal.pbio.2000862

Liddicoat, C., Sydnor, H., Cando-Dumancela, C., Dresken, R., Liu, J., Gellie, N. J., et al. (2020). Naturally-diverse airborne environmental microbial exposures modulate the gut microbiome and may provide anxiolytic benefits in mice. Sci. Total Environ. 701:134684. doi: 10.1016/j.scitotenv.2019.134684

Logsdon, A. F., Erickson, M. A., Rhea, E. M., Salameh, T. S., and Banks, W. A. (2018). Gut reactions: how the blood-brain barrier connects the microbiome and the brain. Exp. Biol. Med. 243, 159-165. doi: 10.1177/1535370217743766

Long-Smith, C., O’Riordan, K. J., Clarke, G., Stanton, C., Dinan, T. G., and Cryan, J. F. (2020). Microbiota-gut-brain axis: new therapeutic opportunities. Annu. Rev. Pharmacol. Toxicol. 60, 477-502. doi: 10.1146/annurev-pharmtox010919-023628

Lyte, J. M., Gheorghe, C. E., Goodson, M. S., Kelley-Loughnane, N., Dinan, T. G., Cryan, J. F., et al. (2020). Gut-brain axis serotonergic responses to acute stress exposure are microbiome-dependent. Neurogastroenterol. Motil. 11:e13881. doi: $10.1111 /$ nmo.13881

Margulis, L. (1990). Words as battle cries: symbiogenesis and the new field of endocytobiology. Bioscience 40, 673-677. doi: 10.2307/1311435

Margulis, L., and Sagan, D. (1986). Microcosmos: Four Billion Years of Microbial Evolution. Berkeley, NJ: University of California Press. doi: 10.1525/ 9780520340510

Moeller, A. H., Caro-Quintero, A., Mjungu, D., Georgiev, A. V., Lonsdorf, E. V., Muller, M. N., et al. (2016). Cospeciation of gut microbiota with hominids. Science 353, 380-382. doi: 10.1126/science.aaf3951

Moran, A. (2012). Thinking in action: some insights from cognitive sport psychology. Thinking Skills Creat. 7, 85-92. doi: 10.1016/j.tsc.2012.03.005

Nguyen, H. T., Pokhrel, A. R., Nguyen, C. T., Dhakal, D., Lim, H. N., Jung, H. J., et al. (2020). Streptomyces sp. VN1, a producer of diverse metabolites including non-natural furan-type anticancer compound. Sci. Rep. 10, 1-4. doi: 10.1038/s41598-020-58623-1

Nguyen, J. C., Rebsamen, S. L., Tuite, M. J., Davis, J. M., and Rosas, H. G. (2018). Imaging of Kingella kingae musculoskeletal infections in children: a series of 5 cases. Emerg. Radiol. 25, 615-620. doi: 10.1007/s10140-018-1617-8

Ochman, H., Worobey, M., Kuo, C. H., Ndjango, J. B. N., Peeters, M., Hahn, B. H., et al. (2010). Evolutionary relationships of wild hominids recapitulated by gut microbial communities. PLoS Biol 8:e1000546. doi: 10.1371/journal.pbio. 1000546

O’Donnell, M. P., Fox, B. W., Chao, P. H., Schroeder, F. C., and Sengupta, P. (2020). A neurotransmitter produced by gut bacteria modulates host sensory behaviour. Nature 17, 1-6. doi: 10.1038/s41586-020-2395-5

Olszewska-Guizzo, A., Sia, A., Fogel, A., and Ho, R. (2020). Can exposure to certain urban green spaces trigger frontal alpha asymmetry in the brain?-Preliminary findings from a passive task EEG study. Int. J. Environ. Res. Public Health 17:394. doi: 10.3390/ijerph17020394
Partan, S., and Marler, P. (2002). The Umwelt and its relevance to animal communication: introduction to special issue. J. Comp. Psychol. 116, 116-119. doi: 10.1037/0735-7036.116.2.116

Pasquaretta, C., Gómez-Moracho, T., Heeb, P., and Lihoreau, M. (2018). Exploring interactions between the gut microbiota and social behavior through nutrition. Genes 9:534. doi: 10.3390/genes9110534

Petra, A. I., Panagiotidou, S., Hatziagelaki, E., Stewart, J. M., Conti, P., and Theoharides, T. C. (2015). Gut-microbiota-brain axis and its effect on neuropsychiatric disorders with suspected immune dysregulation. Clin. Ther. 37, 984-995. doi: 10.1016/j.clinthera.2015.04.002

Preisz, A. (2019). Fast and slow thinking; and the problem of conflating clinical reasoning and ethical deliberation in acute decision-making. J. Paediatr. Child Health 55, 621-624. doi: 10.1111/jpc.14447

Prescott, S. L., Larcombe, D. L., Logan, A. C., West, C., Burks, W., Caraballo, L., et al. (2017). The skin microbiome: impact of modern environments on skin ecology, barrier integrity, and systemic immune programming. World Allergy Organ. J. 10:29. doi: 10.1186/s40413-017-0160-5

Qiao, H., Keesey, I. W., Hansson, B. S., and Knaden, M. (2019). Gut microbiota affects development and olfactory behavior in Drosophila melanogaster. J. Exp. Biol. 222:jeb192500. doi: 10.1242/jeb.192500

Robinson, J. M., and Breed, M. F. (2020). The Lovebug Effect: is the human biophilic drive influenced by interactions between the host, the environment, and the microbiome? Sci. Tot. Environ. 720:137626. doi: 10.1016/j.scitotenv. 2020.137626

Rook, G. A. (2013). Regulation of the immune system by biodiversity from the natural environment: an ecosystem service essential to health. Proc. Natl. Acad. Sci. U.S.A. 110, 18360-18367. doi: 10.1073/pnas.1313731110

Rook, G. A., Raison, C. L., and Lowry, C. A. (2014). Microbiota, Immunoregulatory Old Friends and Psychiatric Disorders: Microbial Endocrinology: The MicrobiotaGut-Brain Axis in Health and Disease. New York, NY: Springer, 319-356. doi: 10.1007/978-1-4939-0897-4_15

Rosenberg, E., and Zilber-Rosenberg, I. (2020). The hologenome concept of evolution: do mothers matter most?. BJOG. Int. J. Obstet. Gynaecol. 127, 129-137. doi: 10.1111/1471-0528.15882

Rottenstreich, Y., Sood, S., and Brenner, L. (2007). Feeling and thinking in memory-based versus stimulus-based choices. J. Consum. Res. 33, 461-469. doi: $10.1086 / 510219$

Sandell, K. (2019). Olfactory cues and purchase behavior: consumer characteristics as moderators. Eur. J. Mark 53:918. doi: 10.1108/EJM-12-2017-0918

Sharon, G., Segal, D., Ringo, J. M., Hefetz, A., Zilber-Rosenberg, I., and Rosenberg, E. (2010). Commensal bacteria play a role in mating preference of Drosophila melanogaster. Proc. Natl. Acad. Sci. U.S.A. 107, 20051-20056. doi: 10.1073/pnas. 1009906107

Sheldrake, M. (2020). The Entangled Life: How Fungi Make our Worlds, Change our Minds, and Shape our Futures. London: Penguin Random House.

Sherwin, E., Bordenstein, S. R., Quinn, J. L., Dinan, T. G., and Cryan, J. F. (2019). Microbiota and the social brain. Science 366:6465. doi: 10.1126/science.aar 2016

Shropshire, J. D., and Bordenstein, S. R. (2016). Speciation by symbiosis: the microbiome and behavior. MBio 7:e10785-15. doi: 10.1128/mBio.01785-15

Simon, J. C., Marchesi, J. R., Mougel, C., and Selosse, M. A. (2019). Host-microbiota interactions: from holobiont theory to analysis. Microbiome 7, 1-5. doi: 10 . 1186/s40168-019-0619-4

Stein, M. M., Hrusch, C. L., Gozdz, J., Igartua, C., Pivniouk, V., Murray, S. E., et al. (2016). Innate immunity and asthma risk in Amish and Hutterite farm children. N. Engl. J. Med. 375, 411-421. doi: 10.1056/nejmoa1508749

Stilling, R. M., Bordenstein, S. R., Dinan, T. G., and Cryan, J. F. (2014). Friends with social benefits: host-microbe interactions as a driver of brain evolution and development? Front. Cell Infect. Microbiol. 4:147. doi: 10.3389/fcimb.2014. 00147

Stres, B., and Kronegger, L. (2019). Shift in the paradigm towards next-generation microbiology. FEMS Microbiol. Lett. 366:fnz159. doi: 10.1093/femsle/ fnz159

Suárez, J. (2020). The stability of traits conception of the hologenome: an evolutionary account of holobiont individuality. Hist. Philos. Life Sci. 42, 1-27. doi: 10.1007/s40656-020-00305-2 
Suárez, J., and Stencel, A. (2020). A part-dependent account of biological individuality: why holobionts are individuals and ecosystems simultaneously. Biol. Rev. 95, 1308-1324. doi: 10.1111/brv.12610

Suárez, J., and Triviño, V. (2020). What is a hologenomic adaptation? Emergent individuality and inter-identity in multispecies systems. Front. Psychol. 11:187. doi: 10.3389/fpsyg.2020.00187

Talbott, S. M., Talbott, J. A., Stephens, B. J., and Oddou, M. P. (2020). Modulation of gut-brain axis improves microbiome, metabolism, and mood. Funct. Foods Health Dis. 10, 37-54. doi: 10.31989/ffhd.v10i1.685

Timmis, K., Cavicchioli, R., Garcia, J. L., Nogales, B., Chavarría, M., Stein, L., et al. (2019). The urgent need for microbiology literacy in society. Environ. Microbiol. 21, 513-528. doi: 10.1111/1462-2920. 14611

Ueno, H., and Nakazato, M. (2016). Mechanistic relationship between the vagal afferent pathway, central nervous system and peripheral organs in appetite regulation. J. Diabet. Investig. 7, 812-818. doi: 10.1111/jdi. 12492

Von Uexküll, J., Beer, T., and Bethe, A. (1899). Vorschläge zu einer objectivierenden nomenklatur in der physiologie des nervensystems. Biol. Centralblatt. 19, 517-521.

Von Uexküll, J. (1934/1957). “A stroll through the worlds of animals and men: a picture book of invisible worlds," in Instinctive Behavior: The Development of a Modern Concept, ed. C. H. Schiller (New York, NY: International Universities Press), 5-80.
Vuong, H. E., Yano, J. M., Fung, T. C., and Hsiao, E. Y. (2017). The microbiome and host behavior. Annu. Rev. Neurosci. 40, 21-49. doi: 10.1146/annurev-neuro072116-031347

Wong, A. C., Holmes, A., Ponton, F., Lihoreau, M., Wilson, K., Raubenheimer, D., et al. (2015). Behavioral microbiomics: a multi-dimensional approach to microbial influence on behavior. Front. Microbiol. 6:1359. doi: 10.3389/fmicb. 2015.01359

Wooley, J. C., and Ye, Y. (2010). Metagenomics: facts and artefacts, and computational challenges. J. Comp. Sci. Tech. 25, 71-81. doi: 10.1007/s11390010-9306-4

Zeki, S., Goodenough, O. R., and Sapolsky, R. M. (2004). The frontal cortex and the criminal justice system. Philos. Trans. R. Soc. Lond. B Biol. Sci. 359, 1787-1796. doi: $10.1098 /$ rstb.2004.1547

Conflict of Interest: The authors declare that the research was conducted in the absence of any commercial or financial relationships that could be construed as a potential conflict of interest.

Copyright (c) 2020 Robinson and Cameron. This is an open-access article distributed under the terms of the Creative Commons Attribution License (CC BY). The use, distribution or reproduction in other forums is permitted, provided the original author(s) and the copyright owner(s) are credited and that the original publication in this journal is cited, in accordance with accepted academic practice. No use, distribution or reproduction is permitted which does not comply with these terms. 